\title{
Capability of pipe inside an actuator to move in various fluid and oil surfaces
}

\section{Hiroyuki Yaguchi*, Keito Murai and Keita Yaegashi}

\author{
${ }^{1}$ Faculty of Mechanical Engineering, Tohoku Gakuin University, \\ 1-13-1 Chuo, Tagajo, Miyagi, Japan \\ *Email: yaguchi@mail.tohoku-gakuin.ac.jp \\ Phone: +81 22368710; Fax: +81 223687070
}

\begin{abstract}
This paper proposes a novel pipe inside a magnetic actuator that operates on the elastic energy of a vibration component excited by electromagnetic force. Flexible material such as rubber was used to support the actuator in the pipe and was used as a means of transferring elastic energy. The actuator is moved by the difference between forward and backward forces of support point of actuator. In the experiment, the actuator that was shielded by a thin acrylic hollow cylinder for movement inside a pipe with an inner diameter of $11 \mathrm{~mm}$ was prototyped. Characteristics of movement for the actuator were measured in air and water. The actuator could climb at $14.1 \mathrm{~mm} / \mathrm{s}$ when pulling a load mass of $30 \mathrm{~g}$. In the water, the speed of the actuator compared to the air was approximately $50 \%$ by viscosity resistance of the water. In addition, a prototype of a new magnetic actuator combined with a memory alloy (SMA) wire and an electromagnetic vibration component was proposed and fabricated. In the actuator, the supporting force inside the pipe can be varied by the SMA wire. The speed of the actuator was measured in a pipe soiled with oil. In a pipe with a coefficient of friction of 0.28 , it can pull vertically at a speed of $2 \mathrm{~mm} / \mathrm{s}$ while generating a traction force of $0.088 \mathrm{~N}$. Experimental results demonstrated that this actuator can be used in various environments such as atmospheric air, underwater, and piping with corroded parts. In the future, it is possible to observe the damaged condition inside the piping by mounting a micro CCD-camera on the actuator.
\end{abstract}

Keywords: magnetic actuator, pipe inside mover, supporting force, frictional force, shape memory alloy.

\section{INTRODUCTION}

There are several pipes in water, gas, and chemical plants. The inspection of existing corrosion and cracks is conducted to find the damage of these pipes. A tool capable of inspecting the condition of a pipe surface is required for safety reasons. Besides, a visual inspecting robot to pick up the damage in small pipes is required. Pipes with an inner diameter from $15 \mathrm{~mm}$ to $45 \mathrm{~mm}$, which is the pipeline size, was used for water and gas services. Many studies have investigated the mechanisms for a robot that is capable of inspection in a thin pipe. The robots include devices using magnetic attraction force [1, 2], shape-memory-alloy wires [3, 4], AC magnetic fields [5-7] from the outside, and electromagnetic motors [8-10]. An actuator combined with an electromagnetic force and mechanical vibration was previously proposed by the authors [11-15]. However, for these robots and actuators, a clean inner wall surface of the pipe is assumed, such as water pipe and plant piping, the pipe inner surface used for many years is contaminated with rust and 
oil. A magnetic actuator of the cable type for movement inside a pipe filled on air and water with an inner diameter of $11 \mathrm{~mm}$ was firstly prototyped. The actuator was shielded by a hollow shield cover. Characteristics of movement for the actuator in air and water were measured in detail. Furthermore, it was assumed that the inner surface of the pipe was contaminated with mold or oil. In order to deal with this problem, a method of changing a supporting force of the actuator by using a shape memory alloy coil was proposed. The movement characteristics of the actuator were inspected by the measurement when the pipe inner wall surface was contaminated with oil. Experimental result demonstrated that the actuator could climb at $2 \mathrm{~mm} / \mathrm{s}$ when pulling a load mass of $9 \mathrm{~g}$. Due to the increase in auxiliary force by using the SMA coil even if the coefficient of friction is small, this actuator produces a tractive force of approximately 1.9 times its own weight. In general, vibration is treated as harmful, and research on vibration analysis [16-18] and vibration control has been conducted [19-22]. On the other hand, an attempt to utilise vibration is an interesting problem. In this paper, in order to achieve in-pipe inspection under various environments, a new actuator was used with resonance vibration for inspection in a piping, which combines a shape memory alloy wire and an electromagnetic actuator, was prototyped and tested. By changing the supporting force on SMA wire, the experimental results show that it is possible to move inside the atmosphere, underwater, and pipe soiled with oil.

\section{METHODS AND MATERIALS}

\section{Structure of A Pipe Inside Magnetic Actuator}

Figure 1 is a diagram of a magnetic actuator that moves within an inner diameter pipe of $11 \mathrm{~mm}$. The actuator consists of a permanent magnet to reinforce the magnetic exiting force, an electromagnet, and a translational helical coil spring and a rubber leg to support the actuator's body in a small pipe. The permanent magnet cylindrical $\mathrm{NdFeB}$ is magnetised in the axial direction. The magnet has a diameter of $8 \mathrm{~mm}$ and height of 3 $\mathrm{mm}$. The surface magnetic flux density measured by using tesla meter is $325 \mathrm{mT}$. The spring is the strong steel type with an outer diameter of $8.0 \mathrm{~mm}$, total free length of 14.0 $\mathrm{mm}$, and the spring constant as $\mathrm{k}=2870 \mathrm{~N} / \mathrm{m}$. The gap between the permanent magnet and the electromagnet is $3 \mathrm{~mm}$. The electromagnet consists of an iron core $1.7 \mathrm{~mm}$ in diameter with 810 turns of $0.14 \mathrm{~mm}$ diameter copper wire. The electrical resistance of the electromagnet is $12.3 \Omega$. The rubber used to support the actuator is constructed from natural rubber and has a length of $22 \mathrm{~mm}$, width of $\mathrm{B} \mathrm{mm}$, and thickness of $1 \mathrm{~mm}$.
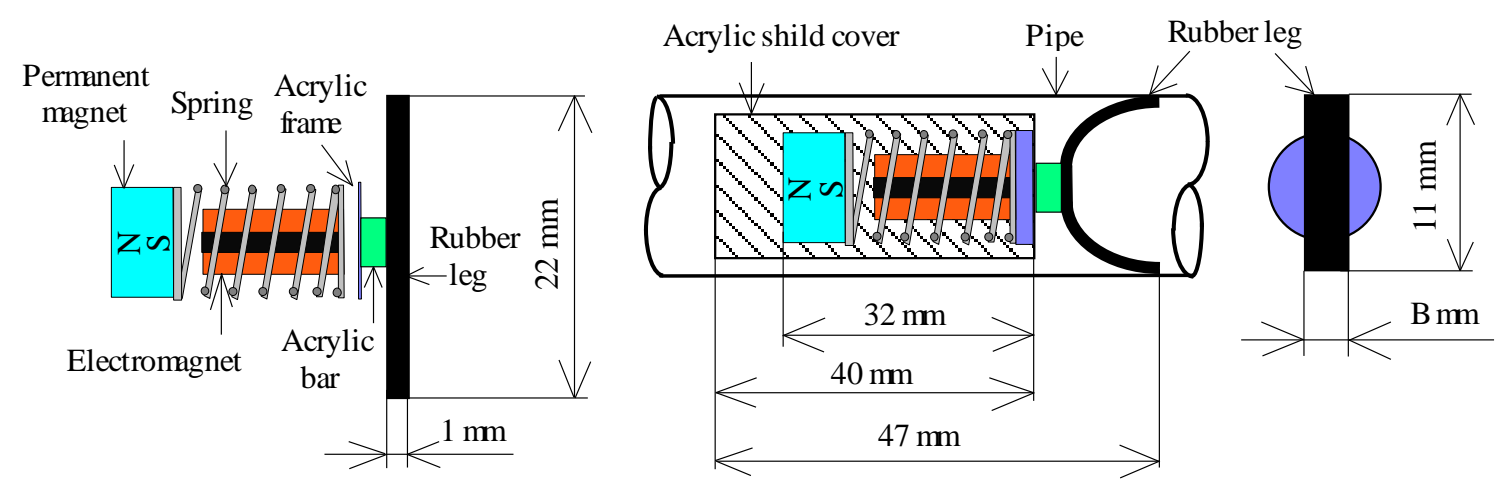

Figure 1. Structure of magnetic actuator. 
The rubber was attached to the frame by a plastic bar having a diameter of $5 \mathrm{~mm}$ as shown in Figure 1. The component constituted by mass- spring vibration model is shielded by a hollow shield cover made of $30 \mathrm{~mm}$ in length, $9.5 \mathrm{~mm}$ in diameter, and acrylic of thickness at $0.2 \mathrm{~mm}$. If the actuator is inserted underwater, the water does not penetrate inside of the vibration component. The actuator is $47 \mathrm{~mm}$ in length and the total mass is $3.8 \mathrm{~g}$. The specifications of the spring and electromagnet are given in Table 1.

Table 1. Specifications of the spring and electromagnet.

\begin{tabular}{lc}
\hline Parameters & Value \\
\hline Spring constant, $k(\mathrm{~N} / \mathrm{m})$ & 2870 \\
Diameter of spring, $d(\mathrm{~mm})$ & 8 \\
Length of spring, $L(\mathrm{~mm})$ & 14 \\
Coil turn of electromagnet & 810 \\
Diameter of electromagnet, $D(\mathrm{~mm})$ & 0.14 \\
Resistance of electromagnet, $R(\Omega)$ & 12.3 \\
\hline
\end{tabular}

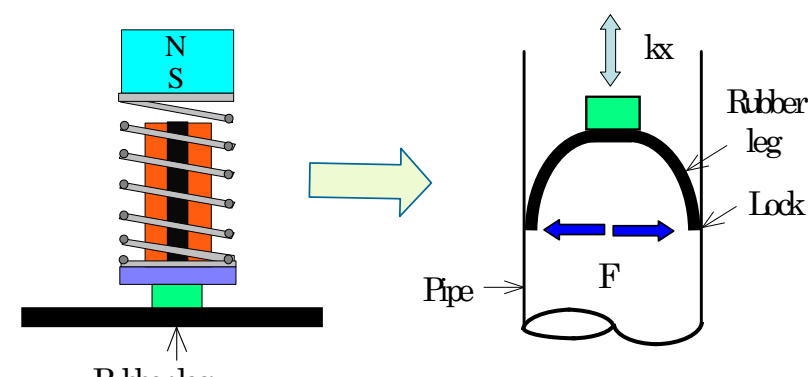

Rubberleg

leg
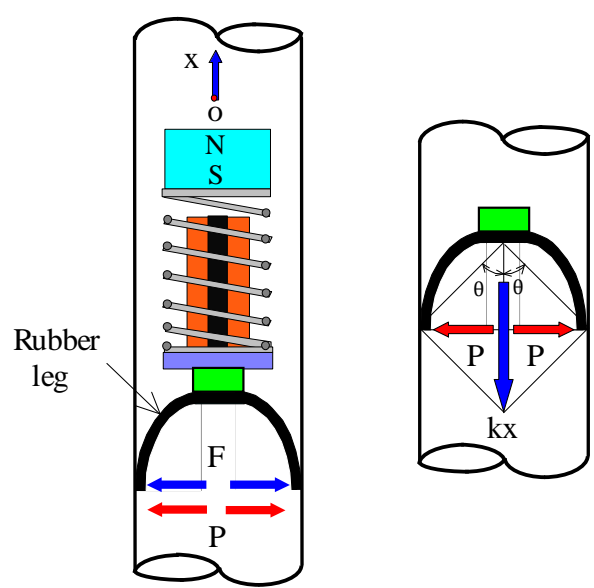

(a) Initial supporting force $\mathrm{F}$

(b) Force acting on inside wall of the pipe due to variable force $\mathrm{P}$ by vibration

Figure 2. Supporting force due to vibration component.

\section{Principle of Motion}

It is assumed that the shielding cover of the vibration component is taken off. The actuator is held in the pipe by the initial supporting force $\mathrm{F}$ by using the rubber leg, as shown in Figure 2. The actuator can be vibrated by having vibration amplitude A because it is held inside the pipe. The alternating inertia force due to vibration of the vibration component is $\mathrm{P}$. When the vibration component is displaced with amplitude $\mathrm{A}$ in the $+\mathrm{x}$ direction, the supporting force $\mathrm{P}(=0)$ is basically unchanged. This means that the actuator slides in the pipe. Conversely, when a vibration component is displaced by amplitude $A$ in the $-x$ direction, the tip of the rubber leg as shown in Figure 2 (a) is transformed, and locked in the pipe inside the wall. If the angle $\theta$ between the rubber leg and pipe wall is 45 degrees, the supporting force of $0.5 \mathrm{kA} \times \sin \theta \cos \theta$ per vibration component acted on the pipe, as shown in Figure 3. In the case of vibration component, the force of approximately 0.25 $\mathrm{kA}$ acts on the pipe. Thus, the actuator moves while alternately sliding and stopping as shown in previous study [15]. 


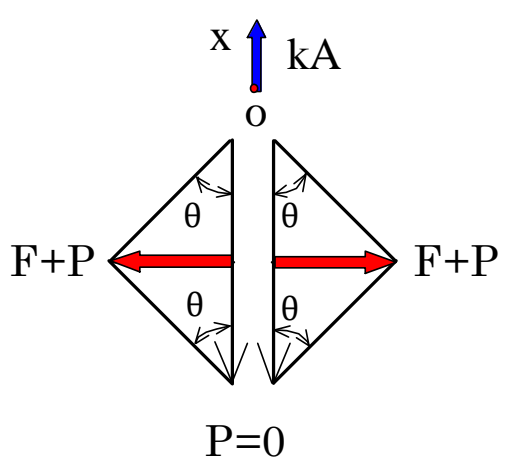

(a) Sliding

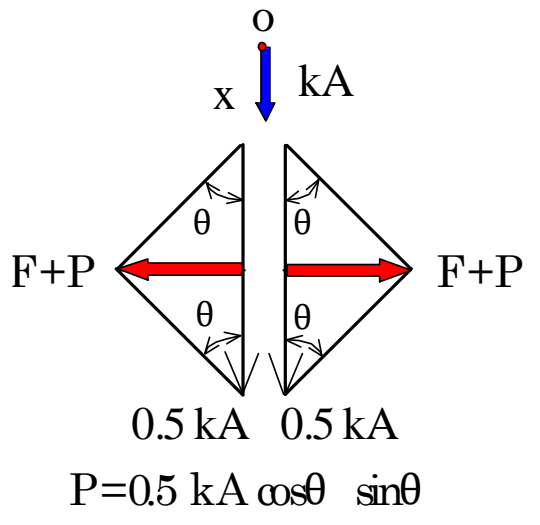

(b) Stopping

Figure 3. Principle of linear motion.

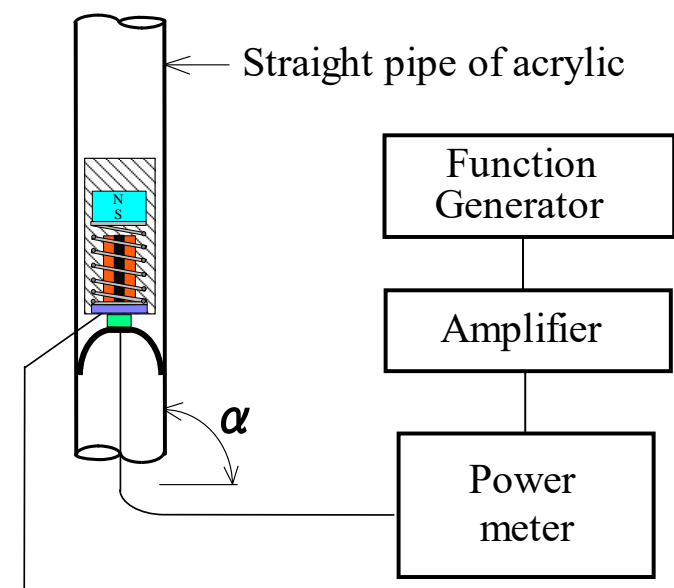

Magnetic actuator

Figure 4. Experimental apparatus.

\section{Basic Movement Characteristics of Magnetic Actuator in Air and Water}

An experimental test was conducted by using an apparatus as shown in Figure 4. The vibration component model was driven at the resonance frequency using a function signal generator and an amplifier. The resonance frequency of this actuator measured by using experimental apparatus was $112 \mathrm{~Hz}$. An acrylic pipe with inner diameter of $11 \mathrm{~mm}$ was used. The coefficient of friction between the rubber leg and the acrylic pipe measured in the experiment was 0.78 . The experimental test of the actuator in the air was firstly carried out. Figure 5 shows the relationship between width B of the rubber leg and supporting force $\mathrm{F}$ of the actuator in the pipe as measured by the force gauge with changing width of $3 \mathrm{~mm}, 4 \mathrm{~mm}, 5 \mathrm{~mm}, 6 \mathrm{~mm}, 7 \mathrm{~mm}$ and $8 \mathrm{~mm}$ of the rubber leg, respectively. The support force increased with increasing width $\mathrm{B}$ of the rubber leg. This was because the bending rigidity in the pipe increased as the width of the rubber leg material increased. When the rubber leg material is held inside the pipe as a cantilever beam, as the rubber width increases, the supporting force of the actuator increases. 


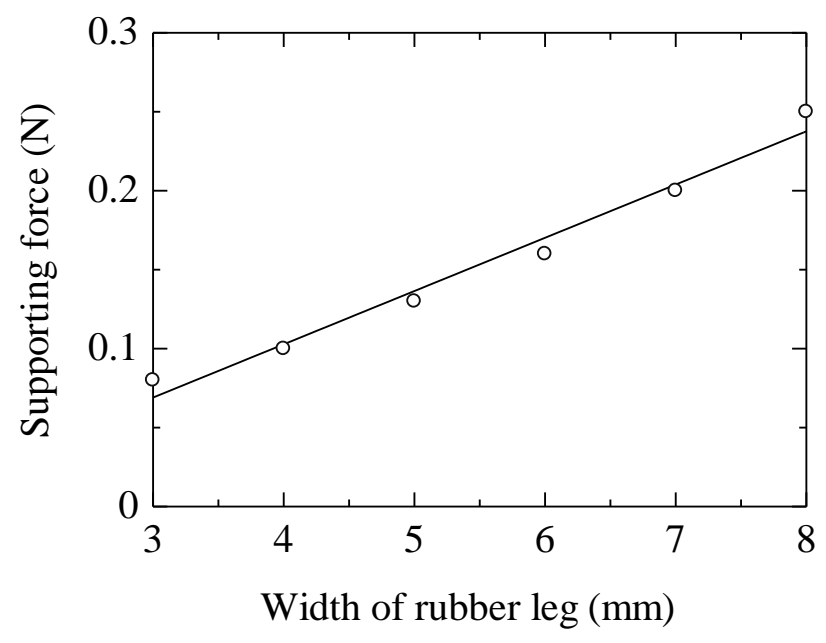

Figure 5. Relationship between width of rubber and vertical upward speed (Air).

Figure 6 shows the relationship between the supporting force $F$ and vertical climb speed of the actuator when input current into the electromagnet was changed to $150 \mathrm{~mA}$, $200 \mathrm{~mA}, 250 \mathrm{~mA}$ and $300 \mathrm{~mA}$. For each supporting force F, an input current maximised the speed of the actuator. The maximum speed of the actuator was $240 \mathrm{~mm} / \mathrm{s}$ when the supporting force F was $0.16 \mathrm{~N}$ and the input current was $300 \mathrm{~mA}$. In Figure 6, an optimal supporting force maximised the speed of the actuator. By using the rubber leg on the optimal flexural rigidity, all of the energy due to the resonance vibration of the vibration component is more efficiently converted into movement in one direction as shown in the previous chapter.

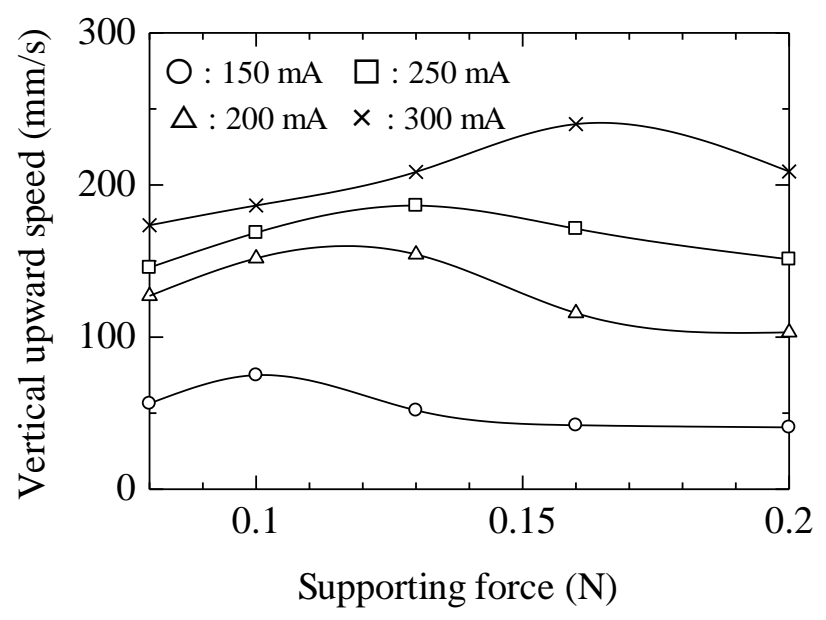

Figure 6. Relationship between supporting force and supporting force (Air).

Figure 7 shows the relationship between the tilt angle $\alpha$ of the pipe and the speed of the actuator when the supporting force $\mathrm{F}$ of the actuator in the pipe was $0.1 \mathrm{~N}, 0.16 \mathrm{~N}$ and $0.2 \mathrm{~N}$ and the input current into the electromagnet was $200 \mathrm{~mA}$. The supporting force $\mathrm{F}$ was changed by varying the width of the rubber leg at $4 \mathrm{~mm}, 6 \mathrm{~mm}$, and $7 \mathrm{~mm}$. The tilt angle varied from $\alpha=-90^{\circ}$ (straight downwards) to $\alpha=90^{\circ}$ (straight upwards). 
In Figure 7, an angle of -90 degrees indicates a vertical downwards, 90 degrees indicates a vertical upwards, and 0 degrees indicates a horizontal movement. The difference between the upwards and downwards speeds for this actuator was about 1.5 times, when the supporting force was $0.1 \mathrm{~N}$. This is due to the effect of the weight of the actuator itself.

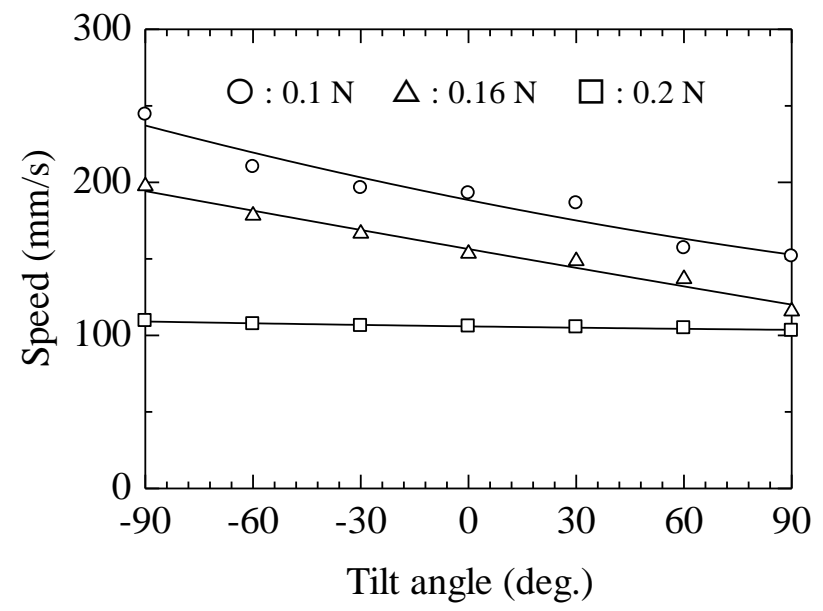

Figure 7. Relationship between angle and speed (Air).

Figure 8 shows the relationship between the load mass loaded in the actuator and the vertical climb speed when the supporting force $\mathrm{F}$ in the pipe was $0.1 \mathrm{~N}, 0.16 \mathrm{~N}$ and $0.2 \mathrm{~N}$ and input current into the electromagnet was $200 \mathrm{~mA}$. This figure indicates that the actuator is able to climb at $14.1 \mathrm{~mm} / \mathrm{s}$ when the load mass is $30 \mathrm{~g}$. This magnetic actuator produces a tractive force of approximately 7.9 times its own weight. This actuator demonstrates a good performance compared to other types of actuators powered by the electric cable, considering this size and mass. On the other hand, an acrylic water had a width of $40 \mathrm{~cm}$, length of $45 \mathrm{~cm}$ and height of $30 \mathrm{~cm}$ was prepared, and water was poured inside. The actuator was inserted in the water tank, and movement properties were measured in air by the same method. In this case, the coefficient of friction and the resonance frequency are the same in the air.

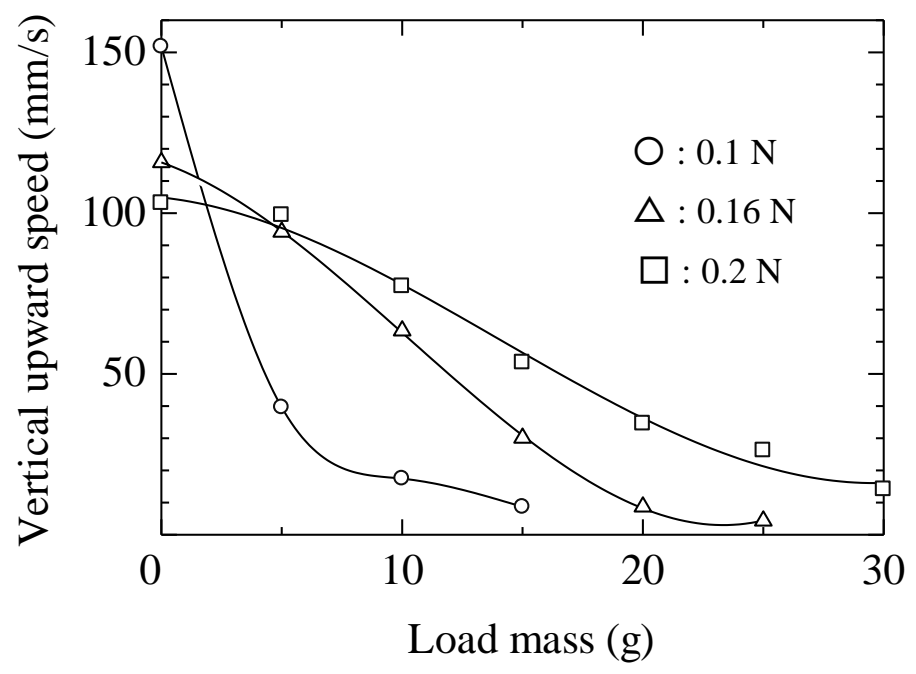

Figure 8. Relationship between load and speed (Air). 
Figure 9 shows the relationship between the tilt angle $\alpha$ of the pipe and the speed of the actuator when the supporting force $\mathrm{F}$ of the actuator in the pipe was $0.1 \mathrm{~N}, 0.16 \mathrm{~N}$ and 0.2 $\mathrm{N}$. The supporting force $\mathrm{F}$ was changed by varying the width of the rubber legs at $4 \mathrm{~mm}$, $6 \mathrm{~mm}$ and $7 \mathrm{~mm}$. In the water, the difference of the upwards and downwards speeds for this actuator was about 1.4 times, when the supporting force was $0.1 \mathrm{~N}$. The ratio of the speed is smaller than in the atmosphere. This is because the density of air and water were different. Figure 10 shows the relationship between the load mass loaded in the actuator and the vertical upward speed when the supporting force $\mathrm{F}$ was $0.1 \mathrm{~N}, 0.16 \mathrm{~N}$ and $0.2 \mathrm{~N}$ and input current into the electromagnet was $200 \mathrm{~mA}$. The actuator could climb at 2.2 $\mathrm{mm} / \mathrm{s}$ when the load mass was $25 \mathrm{~g}$. Viscous resistance of water was greatly increased in water compared to the atmosphere. The movement speeds of the actuator were considerably lower than in the atmosphere.

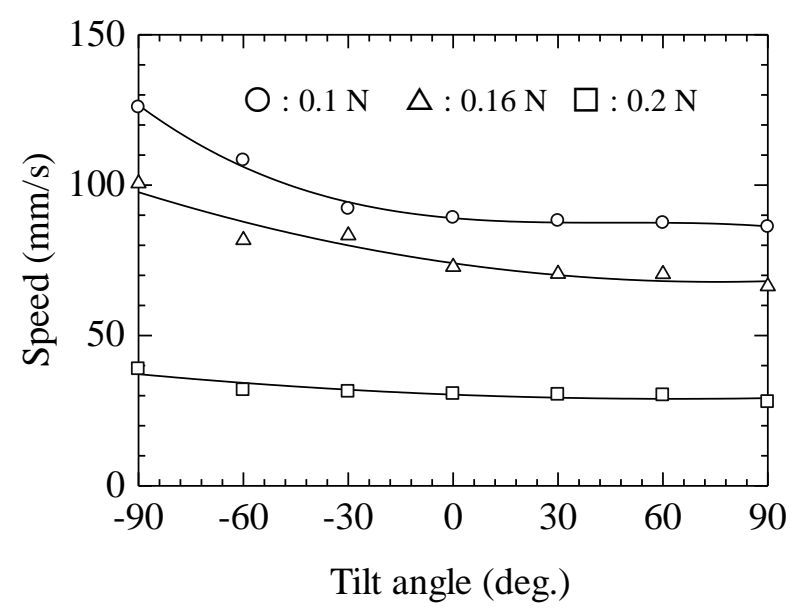

Figure 9. Relationship between angle and speed (Water).

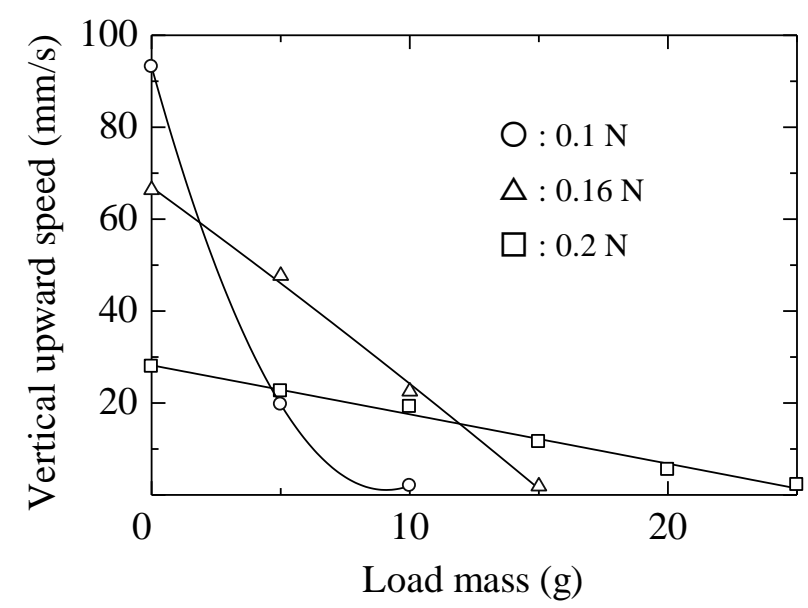

Figure 10. Relationship between load and speed (Water).

Figure 11 shows the relationship between input current into the electromagnet and the vertical upward speed when the supporting force $F$ was $0.1 \mathrm{~N}$. In this figure, $\circ$ and $\Delta$ indicate the experimental values in air and water, respectively. In water, the speed of the 
actuator compared to the air is approximately $50 \%$. Viscous resistance between underwater and the atmosphere is about 45 times. Generally, the viscous resistance force is proportional to square of the speed. As the input current increases into the electromagnet, the speed of the actuator increases. Therefore, when the input current becomes large, the difference between both curves becomes larger.

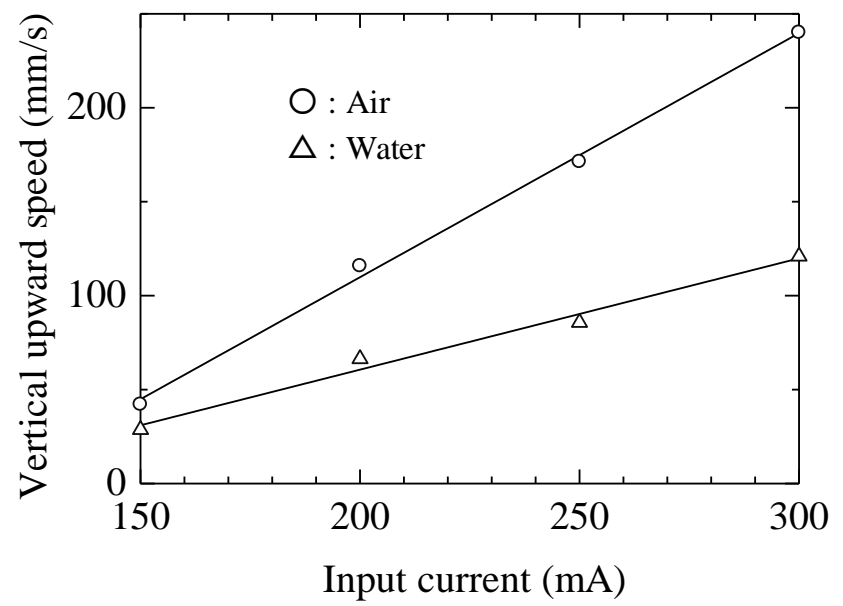

Figure 11. Relationship between input current and speed (Air and Water).

\section{Movement Characteristics as Oil Attaches to the Pipe Surface}

The initial supporting force $\mathrm{F}$ in the pipe of this actuator was decided by the width of the rubber leg. Therefore, for mold or oil attached to the pipe surface, the actuator cannot move as the supporting force F decreases. Two shape-memory-alloy (SMA) coils were attached to the tip of the rubber leg, and the supporting force was changed by using expansion and contraction of SMA coil. The SMA coil is the shape of a spring type with an outer diameter of $0.4 \mathrm{~mm}$ and length of $15 \mathrm{~mm}$ when it is completely contracted. The outer diameter of a SMA coil is $0.15 \mathrm{~mm}$. The SMA coil has an electrical resistance of 400 $\Omega$ per one meter. The electrical resistance of the SMA coil is $6 \Omega$. As shown in Figure 12, the magnetic actuator is composed of the vibration component, two SMA coils labelled A and $\mathrm{B}$, a rubber leg, four copper conductors, four wires and a shielded cover as shown in the previous section. If a direct current is applied to the SMA coil by connecting it to a DC power supply, the SMA coil contracts when the temperature of the SMA coil becomes higher than the transition temperature. From this action, the total supporting force by the rubber leg and two SMA coils can change voluntarily. Table 2 shows the material properties of the SMA coil. The prototyped actuator has a length of $47 \mathrm{~mm}$, and the total mass is $4.8 \mathrm{~g}$. An experimental test was conducted by using an apparatus as shown in Figure 13. To apply electrical current onto two SMA coils, the DC power supply was used. The resonance frequency of the actuator measured by using an experimental apparatus was $112 \mathrm{~Hz}$. Oil film by using spray was evenly spread to the surface of the pipe inside. The acrylic pipe with an inner diameter of $11 \mathrm{~mm}$ was used. The coefficient of friction between the rubber leg and the acrylic pipe measured in the experiment was 0.28 . 

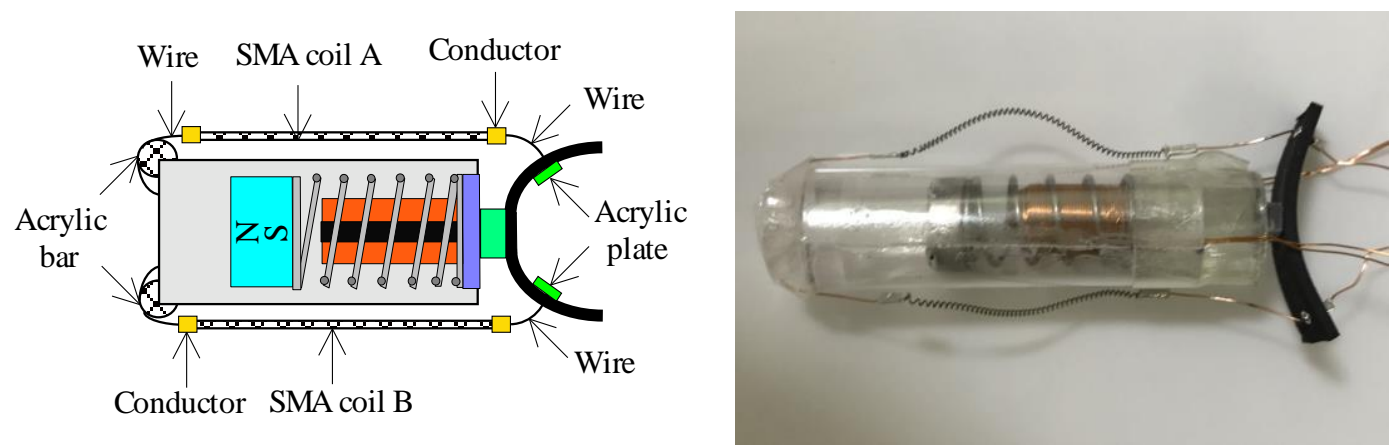

Figure 12. Photograph of the actuator.

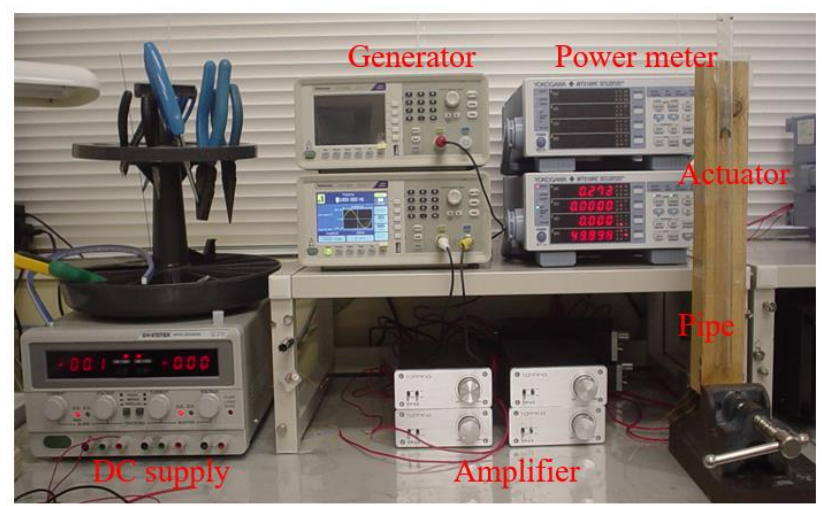

Figure13. Photograph of experimental apparatus.

Table 2. Properties of the SMA coil.

\begin{tabular}{lc}
\hline \multicolumn{1}{c}{ Parameters } & Value \\
\hline Outer diameter $(\mathrm{mm})$ & 0.62 \\
Diameter of wire $(\mathrm{mm})$ & 0.15 \\
Transformation point $\left({ }^{0} \mathrm{C}\right)$ & $50-60$ \\
Resistance per meter $(\Omega)$ & 400 \\
\hline
\end{tabular}

Figure 14 shows the relationship between the time and the total supporting force when direct current into the SMA coil was changed to $150 \mathrm{~mA}$ and $200 \mathrm{~mA}$. The supporting force $\mathrm{F}$ by using the rubber leg with width of $8 \mathrm{~mm}$ was $0.25 \mathrm{~N}$. After 90 seconds, the total supporting force by using two SMA coils and the rubber leg was 0.48 $\mathrm{N}$ and $0.64 \mathrm{~N}$, respectively. The total supporting force changed to the steady state in about 75 seconds. In this paper, the SMA wire of TOKI Corporation (Trademark: BioMetal) was used. This is a feature of BioMetal SMA wire, which takes about 60 seconds to reach the steady state. Figure 15 shows the relationship between the input current into the electromagnet and the vertical upward speed of the actuator when direct current into the SMA coil was changed to $150 \mathrm{~mA}$ and $200 \mathrm{~mA}$ when the supporting force $\mathrm{F}$ was $0.25 \mathrm{~N}$. This figure indicates that the actuator could climb at $63.3 \mathrm{~mm} / \mathrm{s}$ when input current into the electromagnet is $300 \mathrm{~mA}$. The actuator slipped down in the pipe as the direct current into the SMA coil was 0 . When a current of $300 \mathrm{~mA}$ was input to the SMA wire and the supporting force of the actuator was increased, the movement speed of the actuator increased with the increase of the current into the electromagnet. On the other hand, when 
using a current of $200 \mathrm{~mA}$, the movement speed of the actuator decreased. This is because the actuator slipped in the pipe due to low coefficient of friction.

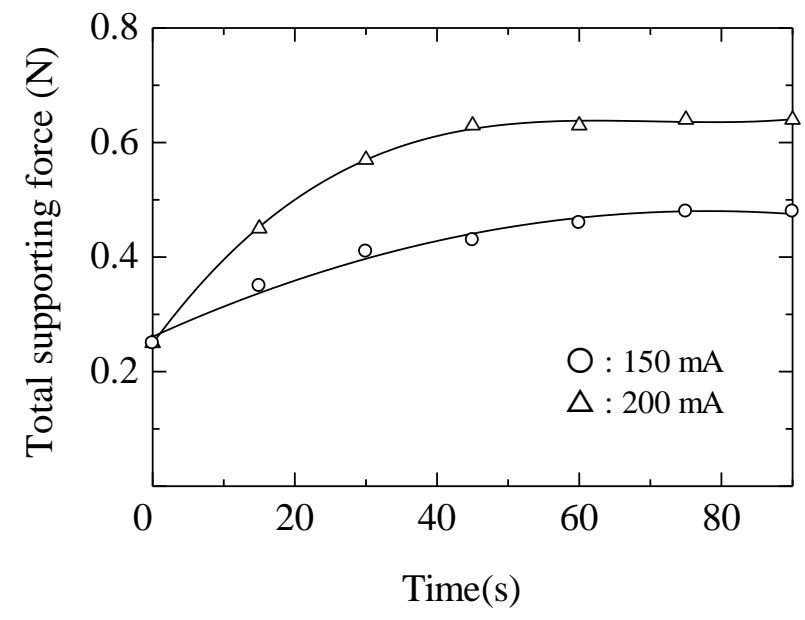

Figure 14. Relationship between time and total supporting force.

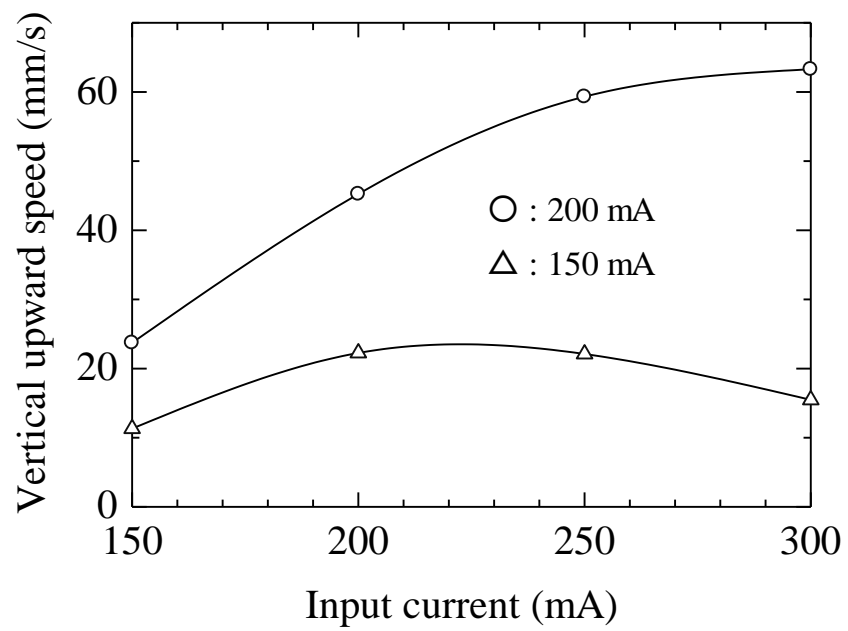

Figure 15. Relationship between input current and speed (Oil).

Figure 16 shows the relationship between the load mass loaded in the actuator and the vertical upward speed when direct current into the SMA coil was changed to $150 \mathrm{~mA}$ and $200 \mathrm{~mA}$ when the supporting force $\mathrm{F}$ was $0.25 \mathrm{~N}$. The input current into the electromagnet was $200 \mathrm{~mW}$. The actuator could climb at $2 \mathrm{~mm} / \mathrm{s}$ when the loading mass was $9 \mathrm{~g}$. Due to the increase in auxiliary force by using the SMA coil even if the coefficient of friction is small, this actuator produces a tractive force of approximately 1.9 times its own weight not shown at a condition in water and oil film [11-15]. The efficiency in the actuator is fairly low. The main reason for the low efficiency is probably because of the transformation loss of energy affected by the rubber leg, in which the resonance energy is transformed into locomotive power as shown in the operational principle in the previous chapter. A high loss is probably not unique to this actuator but inevitable in any actuator for which the propulsion relies on highly frictional pressure applied by an elastic material. A prototype of a new pipe inside actuator combined with a shape memory alloy wire and an electromagnetic actuator was produced. The actuator can vary the supporting force by applying the current to the SMA wire. By setting the initial supporting force on the rubber leg to $0.2 \mathrm{~N}$, the actuator can move under various 
conditions. In pipe soiled with oil, it showed pull characteristics more than twice of its own weight. Furthermore, experimental results demonstrated that it is possible to inspect in pipe soiled with oil as well as with air and water.

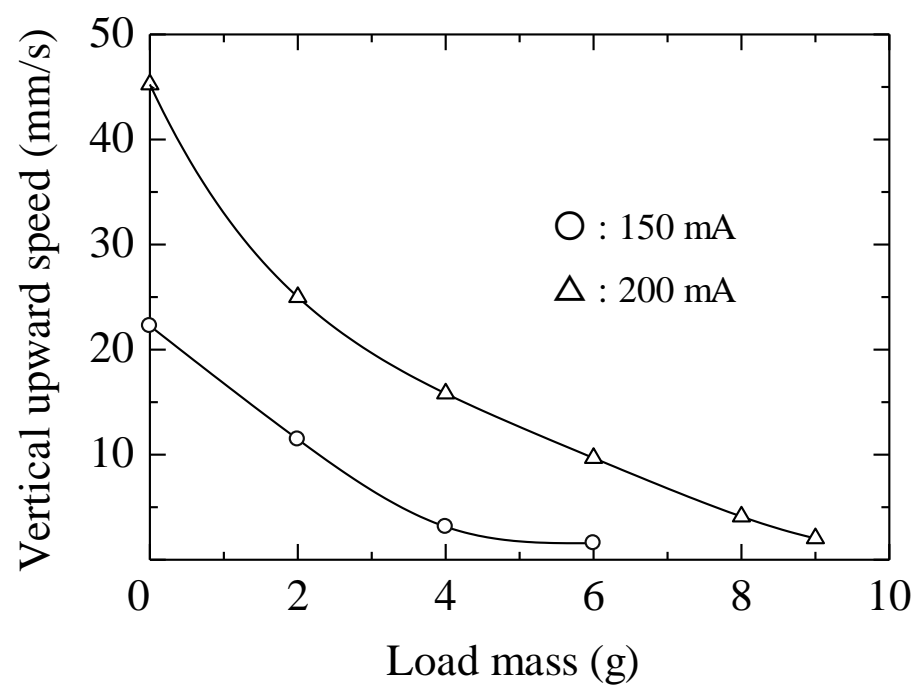

Figure 16. Relationship between input current and speed (Oil).

\section{CONCLUSIONS}

A novel pipe inside magnetic actuator that operates on the elastic energy of a vibration component excited by electromagnetic force is proposed in this paper. Characteristics of movement for the actuator were measured in air and water. In the air, the vertical upward speed of the actuator with no load mass was $240 \mathrm{~mm} / \mathrm{s}$ when an initial supporting force by using the rubber leg was at $0.16 \mathrm{~N}$ and the input current into electromagnet was 300 $\mathrm{mA}$. The actuator could climb at $14.1 \mathrm{~mm} / \mathrm{s}$ when a loading mass was $30 \mathrm{~g}$. Moreover, underwater experiments were conducted under the same conditions. In the water, the performance of the actuator compared to the air was approximately $50 \%$ of the increasing resistance in water. This actuator showed good movement performance in both air and water. In addition, a method of changing the supporting force of the actuator by using two shape memory alloy coils was proposed. Movement tests were carried out in pipe soiled with oil. The actuator could climb at $2 \mathrm{~mm} / \mathrm{s}$ pulling a load mass of $9 \mathrm{~g}$ when the direct current into the SMA coil was $200 \mathrm{~mA}$. Due to the increase in auxiliary force by using the SMA coil even if the coefficient of friction is small, this actuator can move inside the pipe. Based on the measurement results, this actuator demonstrated the possibility of the inspection in the water supply pipes, power generation, chemical plants. The entire actuator must be miniaturised, made lighter and incorporate deployment. Furthermore, by achieving movement inside the curved pipe and mounting a micro CCD-camera, a new inspection technology for piping facilities can be established. However, it is necessary to improve the propulsion power by improving the magnetic circuit of the permanent magnet and the electromagnet in vibration component. Future research will be directed towards these goals.

\section{ACKNOWLEDGEMENT}

We would like to thank the machinery factory of Tohoku Gakuin University that processed the actuator parts. 


\section{REFERENCES}

[1] Li Y, Cheng T, Xuan D, Shen Y. Force characteristic of a magnetic actuator for separable electric connector based on conical airgap. Advances in Mechanical Engineering. 2015;7:168781401556894.

[2] Nagai S, Nozaki T, Kawamura A. Real-time Sensorless Estimation of Position and Force for Solenoid Actuators. IEEJ Journal of Industry Applications. 2016;5:32-8.

[3] Kelemenová T, Frankovský P, Virgala I, Miková L, Kelemen M. Machines for inspection of pipes. Acta Mechatronica. 2016;1:1-7.

[4] Virgala I, Gmiterko A, Kelemen M. Motion analysis of in-pipe robot based on SMA spring actuator. Journal of Automation and Control. 2013;1:21-5.

[5] Kim J, Kim MJ, Yoo J, Kim S-J. Novel Motion Modes for 2-D Locomotion of a Microrobot. IEEE Transactions on Magnetics. 2014;50:1-5.

[6] Choi K, Jang G, Jeon S, Nam J. Capsule-Type Magnetic Microrobot Actuated by an External Magnetic Field for Selective Drug Delivery in Human Blood Vessels. IEEE Transactions on Magnetics. 2014;50:1-4.

[7] Kim SH, Shin JW, Ishiyama K. Multiscale Magnetic Spiral-Type Machines for Fluid Manipulation. IEEE Transactions on Magnetics. 2014;50:1-4.

[8] Guo J, Guo S, Wei X, Gao Q. A Novel tele-operation controller for wireless microrobots in-pipe with hybrid motion. Robotics and Autonomous Systems. 2016;76:68-79.

[9] Shukla A, Karki H. Application of robotics in onshore oil and gas industry-A review Part I. Robotics and Autonomous Systems. 2016;75:490-507.

[10] Guo J, Guo S, Wei X, Wang Y. Development of Wireless Endoscope with Symmetrical Motion Characteristics. International Journal of Advanced Robotic Systems. 2014;11:148.

[11] Yaguchi H, Sato N. Globular Magnetic Actuator Capable of Free Movement in a Complex Pipe. IEEE Transactions on Magnetics. 2010;46:1350-5.

[12] Yaguchi H, Kamata K. In-piping Magnetic Actuator Capable of Inspection in a Thin Complex Pipe. Mechanical Engineering Research. 2012;2.

[13] Yaguchi H. Magnetic Actuator Capable of Inspection in a Complex Pipe by Phase Control of Multiple Electromagnetic Vibration Components. IEEE Transactions on Magnetics. 2015;51:1-4.

[14] Yaguchi H, Sato N, Shikoda A. Magnetic Actuator Group of Globular Type Capable of Free Movement in a Complex Pipe. IEEE Transactions on Magnetics. 2011;47:4159-62.

[15] Yaguchi H, Sasaki K. New type of magnetic actuator system for inspection in a complex pipe. IEEE Transactions on Magnetics. 2013;49:3905-8.

[16] Lee J-Y. Sound and Vibration Signal Analysis using Improved Short-Time Fourier Representation. International Journal of Automotive and Mechanical Engineering. 2013;7:811-9.

[17] Hassan MZ, Magaswaran K, Phuman Singh AS. A new method in the identification of noise and vibration characteristics of automotive disk brakes in the low frequency domain. International Journal of Automotive and Mechanical Engineering (IJAME). 2014;9:1554-77.

[18] Patel CB, Gohil PP, Borhade B. Modeling and Vibration Analysis of Road Profile Measuring System. International Journal of Automotive and Mechanical Engineering. 2010;1:13-28. 
[19] Martynenko G. Resonance mode detuning in rotor systems employing active and passive magnetic bearings with controlled stiffness. International Journal of Automotive and Mechanical Engineering. 2016;13:3293-308.

[20] Kachare PS, Bimleshkumar. Effect of Particle size and packing ratio of PID on vibration amplitude of beam. Journal of Mechanical Engineering and Sciences. 2013;4:504-17.

[21] Khair FA, Putra A, Nor MJ, Selamat MZ. Analysis of sound absorption of hollow tube absorbers. International Journal of Automotive and Mechanical Engineering. 2016;13:3492.

[22] Kob MSC, Supriyo B, Tawi KB, Mazali II. Engagement slip controller development based on actuator displacement for an electro-mechanical friction clutch system. International Journal of Automotive and Mechanical Engineering. 2015;11:2664. 